\title{
Reduced risk of death at 28 days in patients taking a $\beta$ blocker before admission to hospital with myocardial infarction
}

\author{
S M Nidorf, R W Parsons, P L Thompson, K D Jamrozik, M S T Hobbs
}

\begin{abstract}
Objective-To see whether patients taking an oral $\beta$ blocker at the time of admission to hospital with myocardial infarction have a reduced risk of death at 28 days.

Design-Retrospective analysis of data collected on patients admitted over four years.

Setting-Community based study.

Patients-2430 Consecutive patients living in the Perth statistical division admitted to hospital with myocardial infarction during 1984-7.

Main outcome measure-Survival at 28 days among patients taking a $\beta$ blocker at onset of myocardial infarction.

Results-Patients were grouped into those who were and were not taking a $\beta$ blocker at the time of admission. Though patients taking a $\beta$ blocker were older and more likely to have a history of myocardial infarction, angina, or hypertension, the overall mortality at 28 days was similar in the two groups. A logistic regression model used to adjust for factors predictive of cardiac death at 28 days confirmed that patients taking a $\beta$ blocker at the time of admission had a significantly reduced risk of death (relative risk $0 \cdot 50 ; 95 \%$ confidence interval $0 \cdot 34$ to $0 \cdot 76$ ). Though the incidence of fatal ventricular fibrillation was similar in the two groups, mean peak creatine kinase activity was significantly lower in the $\beta$ blocker group.
\end{abstract}

Conclusions-These data support the value of long term use of $\beta$ blockers in patients at risk of myocardial infarction. They suggest that patients taking these agents before admission to hospital with myocardial infarction have a significant survival advantage at 28 days, which may be due to a reduction in infarct size.

\author{
Department of \\ Cardiovascular Medicine \\ and Division of Public \\ Health, Queen Elizabeth II \\ Medical Centre, Nedlands \\ 6009, Perth, Western \\ Australia \\ S M Nidorf, FRACP, \\ cardiology registrar \\ R W Parsons, PHD, \\ biostatistician \\ P L Thompson, FRACP, \\ cardiologist \\ K D Jamrozik, DPHIL, \\ lecturer in public health \\ M S T Hobbs, DPHIL, \\ associate professor in social \\ and preventive medicine
}

Correspondence to: Dr Nidorf, department of cardiovascular medicine.

BrMed f 1990;300:71-4

\section{Introduction}

Though patients taking an oral $\beta$ blocker after acute myocardial infarction have a reduced risk of sudden out of hospital cardiac death and reinfarction, ' it is not known whether these patients continue to derive benefit from this treatment after admission to hospital with myocardial infarction. This study therefore compared morbidity and mortality at 28 days after myocardial infarction in patients who were and were not taking an oral $\beta$ blocker at the time of admission.

Detection of a measurable effect of $\beta$ blockers on 28 day survival in these patients would have important implications regarding their long term use in patients at risk of myocardial infarction and also would help show whether the widespread use of these agents in the community has contributed to the decline in mortality at 28 days after myocardial infarction. ${ }^{23}$

\section{Patients and methods}

We studied data from patients aged 25-64 living within the Perth statistical division who were admitted to hospital with a myocardial infarction during the four years 1984-7. The data form a subset of those collected as part of the MONICA project, an international study conducted under the auspices of the World Health Organisation to monitor trends and determinants of mortality from cardiovascular disease over 10 years. ${ }^{+}$ Prehospital data include each patient's age, sex, smoking habits, and history of cardiovascular disease; medicines being taken at the time of onset of myocardial infarction; and symptoms and complications occurring before arrival at hospital. In hospital data include clinical features on admission, peak plasma creatine kinase activities, cardiac complications, and cardioactive drugs given in hospital. Up to five electrocardiograms for each episode are selected and coded in detail by using the Minnesota system. ${ }^{5}$ Deaths occurring within 28 days after the onset of symptoms of myocardial infarction are determined by review of all death registrations in Western Australia. In accordance with the MONICA protocol episodes of infarction beginning less than 28 days apart are counted only once and each is classified as a "definite" or "possible" infarction according to criteria adopted by the WHO. ${ }^{6}$

Included in the analysis were all patients suffering a definite myocardial infarction as well as those fatal cases diagnosed as possible (these patients had symptoms typical of myocardial infarction but died before confirmation of definite infarction by electrocardiography or enzyme analysis'). Comparison of peak plasma creatine kinase activities was limited to those patients surviving at least 24 hours after admission and who had not had cardiopulmonary resuscitation or DC cardioversion. This was done in order to ensure that true peak creatine kinase activities were measured and that patients with non-cardiac sources of creatine kinase were excluded.

Statistical analysis-The characteristics of patients who were and were not taking a $\beta$ blocker at the time of onset of symptoms of myocardial infarction were compared by $\chi^{2}$ and $t$ tests. Logistic regression was used to determine characteristics predictive of death within 28 days after the onset of symptoms by using the EPIC program. ${ }^{8}$ Variables included in these models were those identified in past studies as having prognostic relevance and those which were biologically important or suggested by preliminary univariate analyses. History of myocardial infarction was recorded as positive if the medical records for the current event included evidence of previous admission to hospital with a clinical diagnosis of myocardial infarction. Where appropriate variables measured on a continuous scale were grouped into categories based on past studies. After including several known prognostic factors in a logistic regression model a variable indicating whether or not the patient was taking a $\beta$ blocker at the time of the present infarct was added. The value of this extra term was assessed by means of a likelihood ratio test. The logistic regression model was also used to determine the expected number of deaths in the 
entire group had $\beta$ blockers not been available by supposing that each patient in the $\beta$ blocker group had the same risk of death as patients in the non- $\beta$ blocker group.

\section{Results}

During 1984-7, 2430 residents of the Perth statistical division under the age of 65 were admitted to hospital with a clinical diagnosis of myocardial infarction. Of these, 2277 had a definite myocardial infarction and 153 patients died of a possible myocardial infarction. Altogether 325 patients died within 28 days of their infarction and 2105 survived this period. A total of $574(24 \%)$ patients with definite or fatal possible myocardial infarction were taking a $\beta$ blocker at the time of onset of symptoms. At discharge 491 (85\%) of these patients were still taking a $\beta$ blocker and half (975) of those in the non- $\beta$ blocker group had started $\beta$ blockers.

Table I compares the clinical details of patients who were and were not taking a $\beta$ blocker at the time of admission. Patients in the $\beta$ blocker group were older, more likely to be women, and more likely to have a past history of acute myocardial infarction, angina, hypertension, and coronary artery bypass surgery. They were also more likely to be non-smokers and to be receiving other forms of treatment, including calcium channel blockers, diuretics, and nitrates. The maximum pulse rate recorded in the first 24 hours after admission was lower in patients taking a $\beta$ blocker $(p<0.001)$ but blood pressure on admission was higher. The frequency of left ventricular failure and the proportion of patients with anterior infarction were almost identical in the two groups.

TABLE I-Clinical details of patients taking and not taking $\beta$ blockers on admission to hospital. Except where stated otherwise figures are numbers (percentages) of patients

\begin{tabular}{|c|c|c|c|}
\hline & $\begin{array}{c}\beta \text { Blocker } \\
\text { group } \\
(\mathbf{n}=574)\end{array}$ & $\begin{array}{c}\text { Non- } \beta \\
\text { blocker } \\
\text { group } \\
(\mathrm{n}=1856)\end{array}$ & $\begin{array}{c}\text { p Value } \\
\left(\chi^{2} \text { test }\right. \\
\left.\text { except }^{\star} \dagger\right)\end{array}$ \\
\hline Male & $441(76 \cdot 8)$ & $1531(82 \cdot 5)$ & 0.002 \\
\hline Mean age (years) & $56 \cdot 7$ & $54 \cdot 5$ & $<0.001^{\star}$ \\
\hline \multicolumn{4}{|l|}{ Past history: } \\
\hline Acute myocardial infarction & $284(49 \cdot 5)$ & $472(25 \cdot 4)$ & $<0 \cdot 001$ \\
\hline Angina & $279(48 \cdot 6)$ & $666(35 \cdot 9)$ & $<0.001$ \\
\hline Hypertension & $451(78 \cdot 6)$ & $575(31 \cdot 0)$ & $<0.001$ \\
\hline Coronary artery bypass graft & $65(11 \cdot 3)$ & $89(4 \cdot 8)$ & $<0.001$ \\
\hline Current smoker & $202(35 \cdot 2)$ & $915(49 \cdot 3)$ & $<0.001$ \\
\hline Ex-smoker & $219(38 \cdot 2)$ & $497(26 \cdot 8)$ & $<0.001$ \\
\hline Time to medical care $<4 \mathrm{~h}$ & $385(67 \cdot 1)$ & $1225(66 \cdot 0)$ & NS \\
\hline \multicolumn{4}{|l|}{ Drugs being taken on admission: } \\
\hline Calcium channel blockers & $105(18 \cdot 3)$ & $244(13 \cdot 1)$ & 0.002 \\
\hline Diuretics & $207(36 \cdot 1)$ & $326(17 \cdot 6)$ & $<0.001$ \\
\hline Digoxin & $16(2 \cdot 8)$ & $113(6 \cdot 1)$ & 0.002 \\
\hline Nitrates & $222(38 \cdot 7)$ & $296(15 \cdot 9)$ & $<0.001$ \\
\hline \multicolumn{4}{|c|}{ Findings during current admission: } \\
\hline $\begin{array}{l}\text { Mean maximum pulse rate in } \\
\text { first } 24 \mathrm{~h} \text { (beats } / \mathrm{min})\end{array}$ & 92 & 97 & $<0.001^{\star}$ \\
\hline $\begin{array}{l}\text { Mean systolic blood pressure } \\
(\mathrm{mm} \mathrm{Hg})\end{array}$ & 141 & 138 & $0.033^{\star}$ \\
\hline Anterior acute myocardial & $248(43 \cdot 2)$ & $765(41 \cdot 2)$ & NS \\
\hline Acute left ventricular failure & $21(3 \cdot 7)$ & $66(3 \cdot 6)$ & NS \\
\hline $\begin{array}{l}\text { Mean peak creatine kinase } \\
\text { activity }(\mathrm{IU} / \mathrm{l})\end{array}$ & 1358 & 1503 & $0.001 \dagger$ \\
\hline
\end{tabular}

tWilcoxon rank test.

There was no significant difference in the overall mortality at 28 days between the $\beta$ blocker and non- $\beta$ blocker groups (76/574 (13.2\%) v 249/1856 (13.4\%); $\mathrm{p}=0.91$ ) (table II). Nevertheless, for patients among whom mortality was expected to be high - for example, those with a past history of myocardial infarction, bypass surgery, or use of diuretics - it was significantly lower at 28 days in those who had been taking a $\beta$ blocker before the onset of the acute event. A similar trend was seen in patients with a history of hypertension.
TABLE II - Univariate analyses of 28 day mortality in the two groups. Figures are numbers (percentages) of patients

\begin{tabular}{|c|c|c|c|}
\hline & $\beta$ Blocker group & $\begin{array}{l}\text { Non- } \beta \text { blocker } \\
\text { group }\end{array}$ & p Value \\
\hline All patients & $76 / 574(13 \cdot 2)$ & $249 / 1856(13 \cdot 4)$ & $0 \cdot 91$ \\
\hline $\begin{array}{l}\text { Past acute myocardial } \\
\text { infarction }\end{array}$ & $38 / 284(12 \cdot 7)$ & $117 / 472(24 \cdot 8)$ & $<0.001$ \\
\hline Patients taking diuretics & $35 / 207(16 \cdot 9)$ & $121 / 326(37 \cdot 1)$ & $<0.001$ \\
\hline $\begin{array}{l}\text { Past coronary artery } \\
\text { bypass graft }\end{array}$ & & & \\
\hline $\begin{array}{l}\text { bypass graft } \\
\text { Hypertension }\end{array}$ & $\begin{array}{r}8 / 65(12 \cdot 3) \\
59 / 451(13 \cdot 1)\end{array}$ & $\begin{array}{l}24 / 89(21.0) \\
95 / 575(16 \cdot 5)\end{array}$ & $0 \cdot 126$ \\
\hline
\end{tabular}

Table III gives the results from the logistic regression model used to determine the predictors of 28 day mortality. The main predictors of death were past history of myocardial infarction; female sex; age; maximum pulse rate recorded during the first 24 hours after admission; and the development of atrial fibrillation, complete heart block, ventricular fibrillation, or pulmonary oedema. Neither site of infarction nor a past history of either hypertension or angina was found to be an independent marker of 28 day mortality in this model. Smoking was associated with a survival advantage, but this was not evident among patients surviving more than 24 hours after admission. Prior use of diuretics, calcium channel blocking agents, digoxin, or nitrates was associated with an increased risk of death at 28 days.

TABLE III-Relative risks of mortality at 28 days (from multiple logistic regression analysis)

\begin{tabular}{lrrr}
\hline & $\begin{array}{c}\text { No of } \\
\text { patients with } \\
\text { each risk } \\
\text { factor }\end{array}$ & Relative risk & $\begin{array}{c}\text { Confidence } \\
\text { interval }\end{array}$ \\
\hline History of acute myocardial & & & \\
$\quad$ infarction & 756 & $1 \cdot 50$ & $1 \cdot 00$ to $2 \cdot 30$ \\
Female & 458 & $1 \cdot 50$ & $1 \cdot 00$ to $2 \cdot 20$ \\
Age $>55$ & 1031 & $2 \cdot 00$ & $1 \cdot 40$ to $2 \cdot 80$ \\
Pulse $>100$ beats/min & 747 & $2 \cdot 90$ & $2 \cdot 00$ to $4 \cdot 00$ \\
Atrial fibrillation & 240 & $1 \cdot 80$ & $1 \cdot 20$ to $2 \cdot 80$ \\
Complete heart block & 134 & $3 \cdot 10$ & $1 \cdot 90$ to $5 \cdot 30$ \\
Ventricular fibrillation & 225 & $8 \cdot 70$ & $5 \cdot 80$ to $13 \cdot 00$ \\
Pulmonary oedema & 225 & $5 \cdot 70$ & $3 \cdot 90$ to $8 \cdot 50$ \\
Current smoker & 1117 & $0 \cdot 50$ & $0 \cdot 40$ to $0 \cdot 80$ \\
Drugs being taken on admission: & & & \\
$\quad$ Diuretics & 533 & $1 \cdot 90$ & $1 \cdot 30$ to $2 \cdot 70$ \\
$\quad$ Calcium channel blockers & 349 & $1 \cdot 40$ & $0 \cdot 90$ to $2 \cdot 20$ \\
$\quad$ Digoxin & 129 & $1 \cdot 70$ & $1 \cdot 00$ to $2 \cdot 90$ \\
$\quad$ Nitrates & 518 & $1 \cdot 50$ & $1 \cdot 00$ to $2 \cdot 30$ \\
$\quad$ Blockers & 574 & $0 \cdot 50$ & $0 \cdot 34$ to $0 \cdot 76$ \\
& & &
\end{tabular}

When the prior use of a $\beta$ blocker was added to the model it was found to be associated with an independent beneficial effect on mortality (relative risk $0.50 ; 95 \%$ confidence interval 0.34 to 0.76 ), which was most evident in patients surviving the first 24 hours after admission (relative risk $0.31 ; 95 \%$ confidence interval $0 \cdot 18$ to 0.54 ) (table IV). The expected overall mortality among the patients at 28 days had no patient been taking a $\beta$ blocker was $14 \cdot 6 \%$ ( 354 deaths) as opposed to the observed figure of $13 \cdot 4 \%$ ( 325 deaths).

TABLE IV-Relative risks associated with prior use of $\beta$ blockers for all patients and for three subgroups based on survival time. (Figures determined by fitting same multiple logistic model as used in table III)

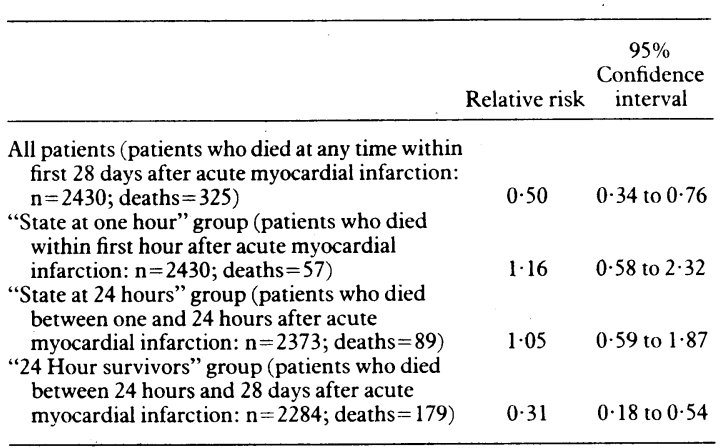


higher proportion of patients in the $\beta$ blocker group $(491 / 574(85 \%) v 975 / 1856$ (53\%) in the non- $\beta$ blocker group) received a $\beta$ blocker in hospital. This explanation also seems unlikely, however, as no published study evaluating the effect of oral $\beta$ blockers begun in hospital after myocardial infarction has been able to show a statistically significant survival advantage by 28 days. ${ }^{11-14}$

A more likely explanation for the observed benefit is that it was due to the prior use of oral $\beta$ blockers. Though there was no evidence of suppression of ventricular fibrillation by the prior use of these agents, our finding that the mean peak creatine kinase activity was lower among patients in the $\beta$ blocker group suggests that established $\beta$ blockade may have conferred a cardioprotective effect by acting to reduce infarct size. This observation is consistent with several studies in which infarct size estimated by measuring total creatine kinase release was found to have been reduced after treatment with intravenous $\beta$ blockers given in the early hours after infarction. ${ }^{10}{ }^{16-18}$ Also in keeping with this suggestion is the observation that patients in the $\beta$ blocker group were no more likely to develop cardiogenic shock despite their higher risk profile. Furthermore, that the protective effect was particularly evident among high risk patients (table II) is consistent with the results of both the ISIS-1 trial (first international study of infarct survival) ${ }^{1}$ and the MIAMI trial (metoprolol in acute myocardial infarction)."

In view of the relative benefit associated with prior use of $\beta$ blockers and the high proportion of patients $(24 \%)$ receiving this treatment at the time of their infarction it seems that $\beta$ blockers have contributed to the decline in 28 day mortality in patients admitted to hospital after myocardial infarction in this community. ${ }^{15}$ We estimate that 29 more deaths would have occurred among these patients had none of them been taking $\beta$ blockers. This represents one death prevented for every 19 patients taking a $\beta$ blocker at the time of onset of symptoms. In contrast, the ISIS-1 study concluded that one life would be saved for every 200 patients treated early with intravenous $\beta$ blocker after myocardial infarction. Taken together, these results are consistent with the hypothesis that the efficacy of $\beta$ blockers in myocardial infarction is dependent on when they are given.

In conclusion, this community based study suggests that prior treatment with oral $\beta$ blockers may confer a "cardioprotective effect" in patients admitted to hospital with acute myocardial infarction. Though this benefit does not seem to be due to a reduction in serious arrhythmias, it may be due to a reduction in infarct size. An important consequence of these data is that they support the long term use of $\beta$ blockers in patients at risk of myocardial infarction. They also suggest that the widespread use of $\beta$ blockers in the community has contributed to the decline in 28 day mortality of patients admitted to hospital with myocardial infarction.

We thank Nicholas de Klerk and Richard Hockey for constructive criticisms of early drafts of this paper.

1 Yusuf S, Peto R, Lewis J, Collins R, Sieight P. Beta blockade during and after myocardial infarction: an overview of the randomized trials. Prog Cardiovasc Dis 1985;27:335-71.

2 Gomez-Martin O, Folsom AR, Kottke TE, et al. Improvement in long term survival amongst patients hospitalized with acute mvocardial infarction, 1920 to 1980. N Engl f Med 1987;316:1353-9.

3 Goldberg R, Szlko M, Tonascia JA, et al. Time trends in prognosis of patients with myocardial infarction; a population based study. Johns Hopkins Medical fournal 1979;144:73-80.

4 Tunstall-Pedoe H. The World Health Organization MONICA project (monitoring trends and determinants in cardiovascular disease): a major (monitoring trends and determinants in cardiovascular disease): a major
international collaboration. Fournal of Clinical Epidemiology 1988;41: internat. $105-14$.

5 Prineas RJ, Crow RS, Blackburn H. The Minnesota code. Manual of electrocardiographic findings. Bristol: John Wright, 1982. blocker group in this study were clearly at a high risk death (table I). Another possible interpretation is that the apparent benefit of a $\beta$ blocker was not dependent on its prior use but rather reflected the fact that a 
6 MONICA Quality Control Centre for Event Registration. MONICA memo 57. Dundee: Ninewells Hospital, 1985.

7 Martin CA. Hobbs MST, Armstrong BK. Measuring the incidence of acut myocardial infarction: the problem of possible acute myocardial infarction. Acta Med Scand 1988;suppl 728:40-7.

8 Statistics and Epidemiological Research Corporation. EPIC epidemiological computer package. Seattle, Washington: Statistics and Epidemiological Research Corporation, 1987.

9 ISIS-1 (First International Study of Infarct Survival) Collaborative Group. Randomised trial of intravenous atenolol amongst 16,027 cases of suspected acute myocardial infarction: ISIS-1. Lancet 1986;ii:57-66.

10 Yusuf S, Sleight P, Rossi PRF, et al. Reduction in infarct size, arrhythmias, chest pain and morbidity by early intravenous beta-blockade in suspected acute myocardial infarction. Circulation 1983;67:32-41.

11 MIAMI Trial Research Group. Metoprolol in acute myocardial infarction (MIAMI). A randomized placebo-controlled trial (with discussants). Eur Heart f 1985; 6:199-226.

12 Göteborg Metoprolol Trial. Effects on mortality and morbidity in acute myocardial infarction. Circulation 1983;67 suppl I):26-32.
13 Pedersen TR. The Norwegian multicenter study of timolol after myocardial infarction. Circulation 1983;67 (suppl I):49-53.

14 Goldstein S. Propranolol therapy in patients with acute myocardial infarction: the beta-blocker heart attack trial. Circulation 1983;67(suppl I):53-7.

15 Thompson PL, Hobbs MST, Martin CA. The rise and fall of ischaemic heart disease in Australia. Aust $N Z$ Z Med 1988;18:327-37.

16 Peter T, Norris RM, Clarke MB, et al. Reduction in enzyme levels by propranolol after acute myocardial infarction. Circulation 1978;57:1091-5.

17 Norris RM, Sammel NL, Clarke ED, Brandt PWP. Treatment of acut myocardial infarction with propranolol. Further studies on enzyme appear ance and subsequent left ventricular function in treated and control patient with developing infarcts. Br Heart $\mathcal{F}$ 1980;43:617-22.

18 Jurgensen SJ, Frederiksen J, Hansen DA, Sen-Bjergorrd DP. Limitation of myocardial infarct size in patients less than 66 years treated with alprenolol. Br Heart F 1981; 45:583-8

(Accepted 30 October 1989 )

\title{
Individual variation between general practitioners in labelling of hypertension
}

\author{
T D W Smith, D Clayton
}

\begin{abstract}
Variation in labelling of hypertension by individual general practitioners was studied during a continuous opportunistic screening progamme for hypertension in a single general practice with 12 principals. All the general practitioners agreed to label as hypertensive patients with systolic pressures of $\geqslant 200 \mathrm{~mm} \mathrm{Hg}$ or diastolic pressures of $\geqslant 110 \mathrm{~mm} \mathrm{Hg}$ on three consecutive readings. The overall number of patients labelled hypertensive at the beginning of the screening programme was 505 and this rose to 801 after five years. There was a large variation in the numbers of patients recorded as hypertensive at the start of the screening period, with numbers ranging from eight to 112 for individual practitioners. The variation persisted during the screening period, with the numbers of patients detected by individual general practitioners ranging from four to 46 . The average systolic and diastolic pressures recorded among these patients also varied between doctors, and only 24 out of 187 patients had their high pressures recorded on three occasions and so fully met the criteria for diagnosing hypertension.

Clearly, general practitioners are following their own individual criteria in defining hypertension and taking into account factors other than just the measured blood pressure.
\end{abstract}

\section{Introduction}

During the course of a computerised blood pressure screening programme in a large general practice we

Variation among individual general practitioners in their labelling of hypertension during screening period 1983-8: numbers of patients detected and their average blood pressures

\begin{tabular}{|c|c|c|c|c|c|c|c|}
\hline \multirow[b]{2}{*}{ Doctor } & \multicolumn{2}{|c|}{ No $(\%)$ hypertensive in: } & \multirow{2}{*}{$\begin{array}{c}\text { No }(\%) \\
\text { detected } \\
\text { by screening }\end{array}$} & \multicolumn{3}{|c|}{$\begin{array}{l}\text { No (and No treated where different) } \\
\text { with systolic } \geqslant 200 \mathrm{~mm} \mathrm{Hg} \text { and } / o r \\
\text { diastolic } \geqslant 110 \mathrm{~mm} \mathrm{Hg} \text { on: }\end{array}$} & \multirow{2}{*}{$\begin{array}{l}\text { Average systolic and } \\
\text { diastolic pressures of all } \\
\text { patients detected during } \\
\text { screening }(\mathrm{mm} \mathrm{Hg})\end{array}$} \\
\hline & 1983 & 1988 & & 3 Readings & 2 Readings & 1 Reading & \\
\hline 1 & $112(22)$ & $126(16)$ & $22(12)$ & 3 & 6 & 13 & $197 / 107$ \\
\hline 2 & $107(21)$ & $160(20)$ & $46(25)$ & $2(1)$ & 12 & $32(28)$ & $185 / 103$ \\
\hline 3 & $53(11)$ & $86(11)$ & $27(15)$ & 6 & $2(1)$ & $19(13)$ & $199 / 110$ \\
\hline 4 & $53(11)$ & $72(9)$ & $12(6)$ & 2 & 3 & 7 & $191 / 109$ \\
\hline 5 & $42(8)$ & $59(7)$ & $22(12)$ & 2 & 3 & $17(14)$ & $178 / 105$ \\
\hline 6 & $31(6)$ & $46(6)$ & $9(5)$ & 0 & 8 & $10)$ & $194 / 108$ \\
\hline 7 & $27(5)$ & $54(7)$ & 158 & 0 & 6 & $9(7)$ & $200 / 105$ \\
\hline 8 & $26(5)$ & $32(4)$ & $6(3)$ & 0 & 2 & $4(3)$ & $173 / 109$ \\
\hline 9 & $20(4)$ & $34(4)$ & $4(2)$ & 3 & 0 & 1 & $206 / 110$ \\
\hline 10 & $14(3)$ & 28 (4) & $7(4)$ & 2 & 3 & $2(1)$ & $177 / 116$ \\
\hline 11 & $12(2)$ & $51(6)$ & $13(7)$ & 3 & 7 & 3 & $193 / 112$ \\
\hline 12 & $8(2)$ & $53(7)$ & $4(2)$ & 1 & 2 & 1 & $195 / 126$ \\
\hline Total & 505 & 801 & 187 & $24(33)$ & $54(53)$ & $109(91)$ & \\
\hline
\end{tabular}

studied the variation among individual general practitioners in their labelling of hypertension.

\section{Methods}

A continuous computerised blood pressure screening programme was undertaken in a large group practice of 12 principals with a list size of about 32000 . Comparison between the individual general practitioners at the start of the screening and after five years was possible as the practice adhered strictly to an individual list system: as far as possible a patient attended the general practitioner he or she was registered with.

All patients aged 40 to 65 years were identified from the age-sex register, and if a normal blood pressure (systolic $\leqslant 160 \mathrm{~mm} \mathrm{Hg}$ and diastolic $\leqslant 100 \mathrm{~mm} \mathrm{Hg}$ ) had not been recorded in their notes within the preceding five years the notes were tagged to alert the general practitioner to measure blood pressure when the patient next attended.

Although there was disagreement over whether to treat mild to moderate levels of raised blood pressure, all the general practitioners agreed that a patient should be labelled hypertensive when three readings of systolic pressure $\geqslant 200 \mathrm{~mm} \mathrm{Hg}$ or diastolic pressure $\geqslant 110 \mathrm{~mm} \mathrm{Hg}$ were recorded. ${ }^{2}$

\section{Results}

From 1983 to 1988 the population to be screened increased by 1856 people through people moving in and out of the practice and age group. The table shows the numbers of patients labelled hypertensive by each general practitioner at the start of the screening programme and after five years of screening.

At the start of screening there were 8800 people aged $40-65$ years. Of these $505(5.7 \%)$ were labelled hypertensive, although the numbers of such patients varied from eight to 112 for individual general practitioners. After five years of screening the total population was 10655 , of whom $801(7 \cdot 5 \%)$ were labelled hypertensive, with numbers for each general practitioner ranging from 28 to 160 . The number of patients labelled hypertensive during the screening period ranged from four to 46.

None of the general practitioners adhered fully to the criteria for labelling hypertension. Of the 187 patients labelled hypertensive during screening only 24 $(12 \cdot 8 \%)$ had had three readings. Overall only $78(42 \%)$ patients had had two or three readings that fulfilled the 